\title{
Editorial
}

\section{Bioprospecting: a CAM Frontier}

\author{
Edwin L. Cooper
}

\section{What is Bioprospecting in Relation to CAM?}

With Volume 2 of $e C A M$, we begin to intensify the inclusion of complementary and alternative medicine (CAM)-related natural products derived from plants and from animals (1). There will be an attempt to focus on products from animals, since we know that the literature tends to be 'glutted' with products derived from plants $(1,2)$. In either case, both sources of natural products provide a veritable cornucopia of sources of new CAM approaches that will emerge as important for future applications, including compounds isolated from marine microorganisms and phytoplankton, green algae, brown algae, red algae, fungi and certain well-known marine and terrestrial animals: sponges, coelenterates, bryozoans, molluscs, tunicates, echinoderms, earthworms and leeches $(3,4)$. Very briefly, there has been an emphasis on new compounds (677 in 2002), together with their relevant biological activities, source organisms and country of origin. As a result, syntheses that lead to the revision of structures or stereochemistries have been included (114), including any first total syntheses of a marine natural product (5).

The prefix bio of course signifies life, and prospecting is defined in several ways: 'an extensive view of a landscape, a mental view of matters; an expectation, a possibility; a chance of success or advancement; a possible customer or client; to explore in search of something.' When put together, they fit the kinds of searches that will be explored in $e C A M$. Actually Muller has recently legitimized the terminology, and our rapid grasp of this possibility is now being rigorously exploited for the good of CAM $(6,7)$ - a kind of resurrection of approaches used to define antibiotics and anticancer molecules (8). Because the literature concerning plants (herbals) is well documented (crowded and found in diverse journals), and because of space, this editorial will focus on a few selected examples of products from one particular animal group. This tack highlights the

Laboratory of Comparative Neuroimmunology, Department of Neurobiology, David Geffen School of Medicine at UCLA, University of California, Los Angeles, CA 90095-1763, USA. Tel: 310-825-9567, Fax: 310-825-2224

Email: ecam@mediet.ucla.edu growing importance of a seemingly new area of work. In fact, many of these investigations are not new, but it is their reorientation toward more practical concerns that has driven this quest away from the search for the sake of the exotic animals themselves. Many of us, the new prospectors, began as biologists, comparative immunologists and invertebrate immunologists (8-10). Eureka in the words of Archimedes! Not about the physical principle concerning water, but about the existence of applicability of molecules derived from invertebrate immune systems! Clearly this firm grounding in biology and the resulting amalgam with immunology will lie at the forefront of efforts to bolster the pursuit or attempts at bioprospecting.

\section{Organismic Benefits of Bioprospecting}

The first objective in a serious approach to CAM should be to obtain a broad understanding, with a minimum of detail, of how CAM fits into the pattern of biology — of the way in which the neuroendocrine immune system evolved, its function and coordination with other body systems, and its development from the embryo onwards $(11,12)$. At the same time, such an outline should provide an adequate background for easy application of CAM ideas to the detail of practical CAM work in public health, clinical and medical practice, and yet not stray far away from the very biology that underpins it. CAM is organismic, inclusive and not exclusive. This organismic approach involving the cells, tissues, organs and the molecules that they synthesize and secrete has fostered and indeed uncovered an incredible systemic amalgam, discovering almost daily an infinite array of new connections and interconnections, revealing ever more minute complexities almost to the point of incomprehension - as vast as the universe.

\section{Effective Compounds from a Pivotal Marine Group: the Sponge as Paradigm}

According to Müller et al., nature, especially the marine environment, provides the most effective drugs used in human therapy (6). Among the metazoans, the marine sponges (phylum

(C) The Author (2005). Published by Oxford University Press. All rights reserved.

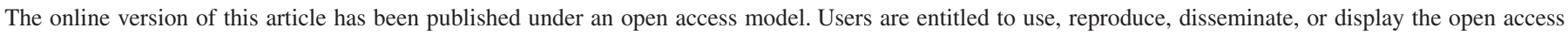

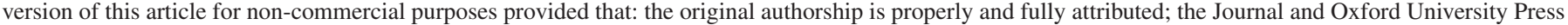

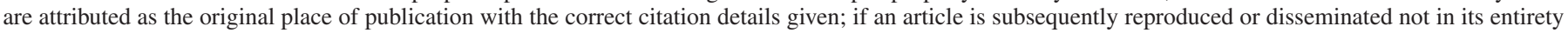
but only in part or as a derivative work this must be clearly indicated. For commercial re-use, please contact journals.permissions@oupjournals.org 
Porifera), which are sessile filter feeders, produce the most potent and highly selective bioactive secondary metabolites. These animals (or their associated symbiotic microorganisms) synthesize secondary metabolites whose activity and selectivity have developed during their long evolutionary history (evochemistry). Pharmaceuticals prepared from marine animals, primarily sponges, have been applied since ancient times (Hippocrates, Aristotle and later Plenius). It has been reported that extracts and/or components from sponges can be used for the treatment of specific diseases. For a systematic and applied-oriented exploitation, the successful development of effective compounds largely depends on the quality of the institutional infrastructure of marine stations and more so on the biodiversity.

It is now established that the basic structural and functional elements are highly conserved from sponges to the crown taxa with the Protostomia (Drosophila melanogaster and Caenorhabditis elegans) and Deuterostomia (human) (13); therefore, it is obvious that the molecular etiology of diseases within the metazoan animals may have a common basis (7). Hence, the major challenge for scientists analyzing natural product chemistry is to elucidate the target(s) of a particular secondary metabolite that is per se highly active and selective. After this step, the potential clinical application can be approached. Examples of compounds that are already in medical use [inhibition of tumor/virus growth (arabinofuranosyl cytosine and arabinofuranosyl adenine)], or are being considered as lead structures [acting as cytostatic and anti-inflammatory secondary metabolites (avarol/avarone), causing induction of apoptosis (sorbicillactone)] or as prototypes for the interference with metabolic pathways common in organisms ranging from sponges to humans [modulation of pathways activated by fungal components (aeroplysinin), inhibition of angiogenesis (2-methylthio-1,4-naphthoquinone), immune-modulating activity (FK506)] are discussed in this study. In addition, bioactive proteins from sponges are listed [antibacterial activity (poreforming protein and tachylectin)]. The goal for the future is to successfully introduce some of these compounds in the treatment of human diseases in order to raise the public awareness on the richness and diversity of natural products, which should be sustainably exploited for human benefit.

\section{Philosophical Underpinning: a Cautionary Note}

At the outset, let us get it straight with respect to the growing position of complementary medicine in the 21 st century most especially in the context of presenting natural products in relation to CAM. According to Wallis (14) 'philosophers and scientists often dismiss complementary and alternative medicine as 'pseudoscience'. In applying the pseudoscience moniker, they often intend to suggest that the beliefs and practices of CAM are as irrational as a fear of flying, as effective as a rabbit's foot and as pretentiously deceptive as a mongrel in a dog show. Many people in Western society have come to think of science as the deity of reason and pseudoscience is its doppelganger' (i.e. double). Wallis has portrayed pseudoscientific beliefs and practices as resulting from human, but nevertheless unacceptable, hypotheses, evidence standards and innate judgment mechanisms. Likewise, science while striving towards laudable intellectual standards should not be thought of as an epistemic authority before which one must unthinkingly genuflect. Let us beware as we continue this quest. Actually these points are appropriate in the context of our resurrection of countless remedies often anecdotal but that are beginning to gain scientific credence in our search for better quality of life.

The paradox of all this newer enthusiasm from the West and historical continuity from Asia prompts a simple explanation. An amalgamation does occur perhaps across the Pacific as it were. As the East becomes more affluent, it has tended to adopt the ways, views and treatments of the West, whereas the already somewhat more affluent West searches for the wisdom of the East and begins to embrace attributes associated with Eastern philosophies and practices. Linkage is reflected in the bridge on the cover of $e C A M$, and bioprospecting offers great possibilities for this linkage. The earthworm, for example, has long been used, e.g. in Chinese and Ayurvedic medicine for various ailments, and now as one of the numerous targets of bioprospecting is coming into Western medicine in the form of lumbrokinase to treat blood clots $(3,8)$. How far can this bridge take us? I seriously doubt that in the immediate future an amalgam of these philosophies and practices, whether from the East or the West, will do anything to prevent the inevitable demise of the organism. However, we do live longer, especially in the more industrial countries where there is greater access to public health care, Western approaches and the increasing acceptance of CAM. Yet despite this enormous wealth, there are still pockets of helplessness internationally that will persist as a challenge. Nevertheless, we can continue to strive through prospecting, perhaps knowing full well that we will not find the true 'fountain of youth'. In this process of perseverance, the quality of our limited days on earth [Biosphere I (15)] will be enhanced considerably and we can and will manage certain maladies (e.g. diabetes), through newer drug discoveries, development of certain vaccines and more focused and analyzed applications of ancient remedies. This is a reasonably accessible goal for basic scientists and clinicians; CAM can aid this quest by providing the bridge.

\section{References}

1. Cooper EL. Drug discovery, CAM and natural products. eCAM 2004;1: 215-7.

2. Roch P. What can we learn from marine invertebrates to be used as complementary and alternative medicine? In: Cooper, EL, Yamaguchi N (eds) Complementary and Alternative Approaches to Biomedicine. Kluwer Academic/Plenum Publishers, New York, 2004, 391-404.

3. Cooper EL, Ru B, Weng N. Earthworms: sources of antimicrobial and anticancer molecules. In: Cooper EL, Yamaguchi N (eds) Complementary and Alternative Approaches to Biomedicine. Kluwer Academic/Plenum Publishers, New York, 2004, 359-90.

4. Roch P Beschin A, Bernard E. Antiprotozoan and antiviral activities of non-cytotoxic truncated and variant analogues of mussel defensin. $e C A M$ 2004;1:167-74.

5. Blunt JW, Copp BR, Munro MH, Northcote PT, Prinsep MR. Marine natural products. Nat Prod Rep 2004;21:1-49. 
6. Müller WEG, Batel R, Schröder HC, Müller IM. Traditional and modern biomedical prospecting: part I-the history sustainable exploitation of biodiversity (sponges and invertebrates) in the Adriatic Sea in Rovinj (Croatia) eCAM 2004;1:71-82.

7. Müller WEG, Schröder HC, Wiens M, Perović-Ottstadt S, Batel R, Müller IM. Traditional and modern biomedical prospecting: part II-the benefits approaches for a sustainable exploitation of biodiversity (secondary metabolites and biomaterials from sponges). eCAM 2004;1:133-44.

8. Cooper EL, Hrzenjak TM, Grdisa M. Alternative sources of fibrinolytic, anticoagulative, antimicrobial and anticancer molecules. Int J Immunopathol Pharmacol 2004; 17:237-244.

9. Beck G, Sugumaran M, Cooper EL (eds). Phylogenic perspectives on the vertebrate immune system. Adv Exp Med Biol 2001;484:1-383.

10. Cooper EL, Beschin A, Bilej M. A New Model for Analyzing Antimicrobial Peptides with Biomedical Applications. IOS Press, Amsterdam, 2002.
11. Cooper EL. Complementary and alternative medicine, when rigorous, can be science. eCAM 2004:1:1-5.

12. Kasahara S, Cooper EL. Nervous, endocrine, immune systems as a target for complementary and alternative medicine. In: Cooper EL, Yamaguchi N (eds) Complementary and Alternative Approaches to Biomedicine. Kluwer Academic/Plenum Publishers, New York, 2004, 405-26.

13. Cooper EL, Kauschke E, Cossarizza A. Digging for innate immunity since Darwin and Metchnikoff. Bioessays 2002;24:319-33.

14. Wallis CS. Scientific thinking: its history, methods, and advantages. In: Cooper EL, Yamaguchi $\mathrm{N}$ (eds) Complementary and Alternative Approaches to Biomedicine. Kluwer Academic/Plenum Publishers, New York, 2004, 427-44.

15. Walford RL, Harris SB, Gunion MW. The calorically restricted low fat nutrient-dense diet in Biosphere 2 significantly lowers blood glucose, total leukocyte count, cholesterol, and blood pressure in humans. Proc Natl Acad Sci USA 1992;89:11533-7. 




The Scientific World Journal
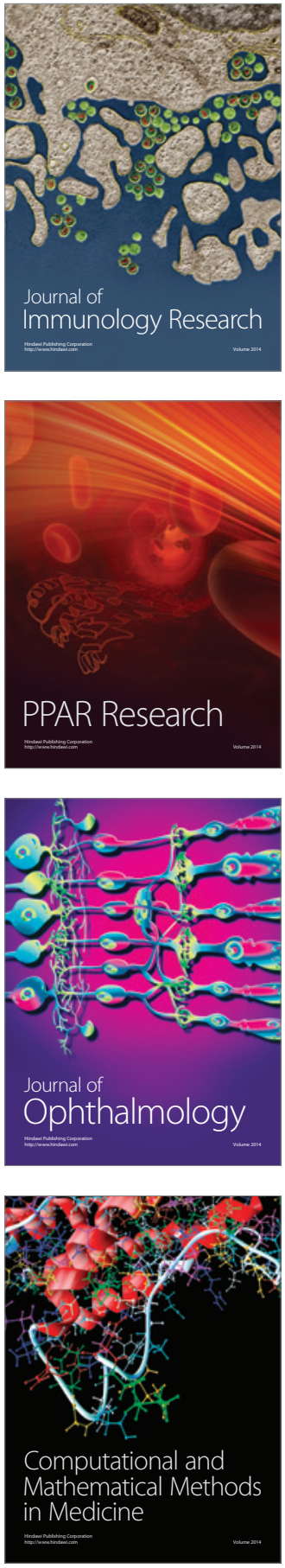



Gastroenterology

Research and Practice
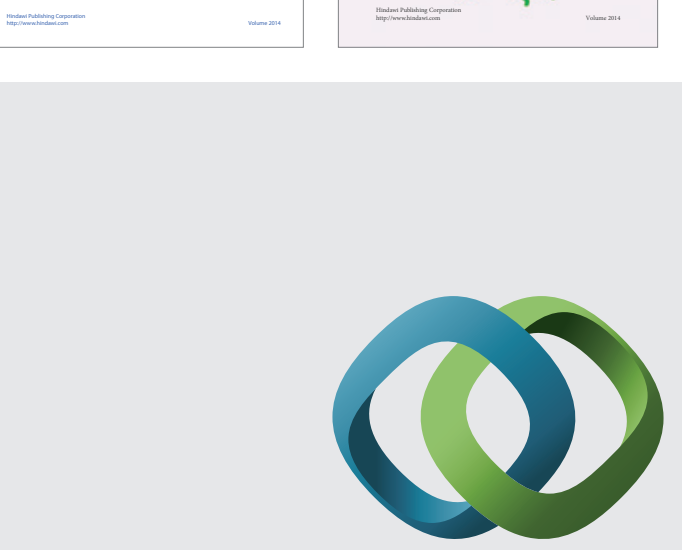

\section{Hindawi}

Submit your manuscripts at

http://www.hindawi.com
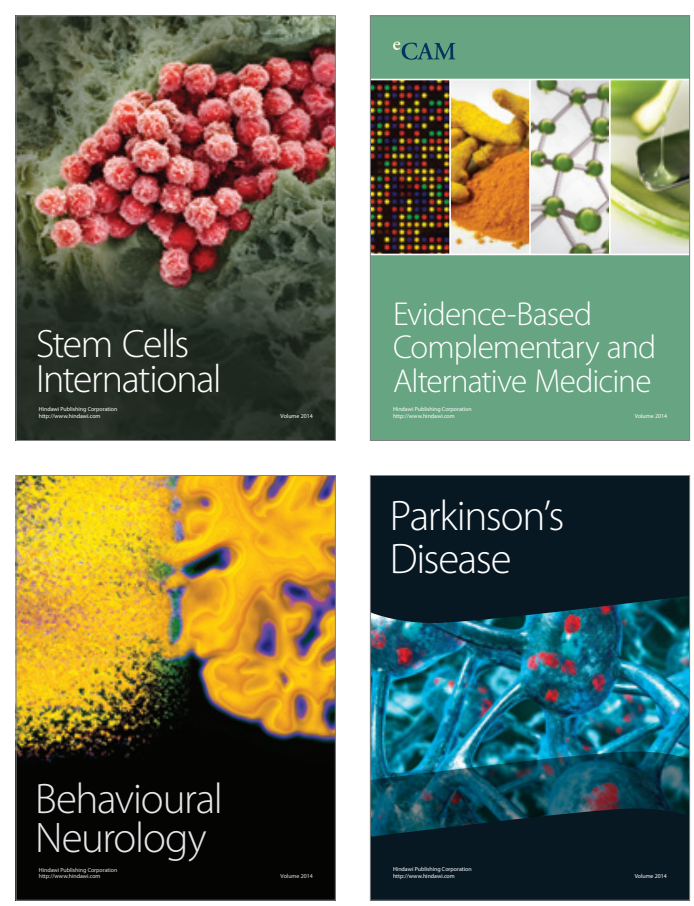

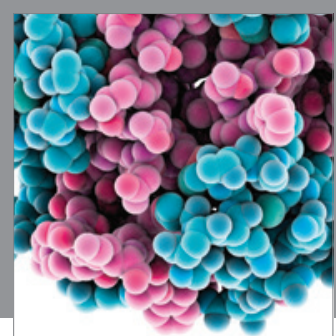

Journal of
Diabetes Research

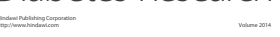

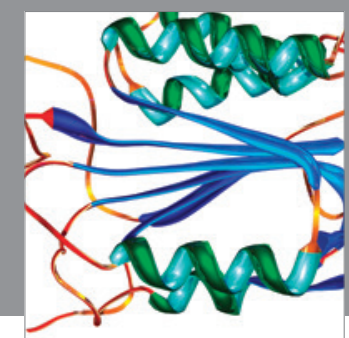

Disease Markers
